\title{
Ação linguístico-comunicativa e práticas discursivas em esferas públicas na sociedade em rede
}

\author{
Language-communicative action and discursive practices in public spheres in the \\ network society \\ Úrsula Cunha Anecleto* \\ Universidade do Estado da Babia, Conceição do Coité, Bahia, Brasil
}

\begin{abstract}
Resumo: Este artigo apresenta bases teóricas para fundamentar estratégias de reestruturação das ações discursivas nas esferas públicas mediadas por tecnologias digitais, na sociedade em rede. Nesse sentido, o estudo ancora-se na Teoria do Agir Comunicado, do filósofo alemão Jürgen Habermas, e na concepção de sociedade em rede, do sociólogo Manuel Castells. Partiu-se do pressuposto de que esses espaços públicos são esferas interacionais, que visam a formação de consensos entre falantes e ouvintes, pelo melhor argumento. Esses ambientes comunicativos, ao oferecerem novas formas de interação, exigem dos sujeitos a ampliação de capacidades linguísticas e comunicativas para, assim, testarem pretensões de validez sobre o mundo e criarem espaços de diálogos, crítica, negociações e entendimento mútuo. As práticas discursivas, então, se constituem em importantes mecanismos na formação do sujeito emancipado, livre para participar de interlocuções nas esferas públicas contemporâneas, a partir de padrões éticos e morais.
\end{abstract}

Palavras-chave: Ação discursiva. Esferas públicas comunicacionais. Ação linguístico-comunicativa.

\begin{abstract}
This article presents theoretical bases to support restructuring strategies of discursive actions in the public spheres mediated by digital technologies in the network society. In this sense, the study is anchored in German philosopher Jürgen Habermas Theory of Agir Comunicado, and in sociologist Manuel Castells conception of a network. It was based on the assumption that these public spaces are interactive spheres, aimed at forming consensuses between speakers and listeners, for the best argument. These communicative environments, by offering new forms of interaction, require the subjects to expand their linguistic and communicative capacities to test validity claims on the world and to create spaces for dialogue, criticism, negotiation and mutual understanding. Discursive practices, then, constitute important mechanisms in the formation of the emancipated subject, free to participate in interlocutions in contemporary public spheres, based on ethical and moral standards.
\end{abstract}

Keywords: Discursive action. Communication public spheres. Linguistic-communicative action.

\section{INTRODUÇÃO}

$\mathrm{Na}$ efervescência do contexto espaço-temporal contemporâneo, com o desenvolvimento das tecnologias digitais e da internet, relações sociais passaram a ser interconectadas e multidimensionais, resultando, assim, em uma sociedade em rede. Esse tipo de sociedade, assim denominada pelo sociólogo Manuel Castells (1999), apresenta como princípio norteador a interatividade e as práticas discursivas mediadas por computadores, o que proporcionou o surgimento de redes horizontais de comunicação.

A morfologia dessas redes promoveu transformações sociais, tendo como fatores importantes a facilidade de acesso e a ampliação de canais comunicativos. Nessa conjuntura, a virtualidade e a interação são elementos constitutivos das

\footnotetext{
* Professora do Departamento de Educação, da Universidade do Estado da Bahia (UNEB / campus XIV), Conceição do Coité - Bahia - Brasil. Email: ursula.cunha@hotmail.com.
} 
práticas comunicativas cotidianas, gerando, dessa forma, outras formas discursivas a partir de novas competências linguístico-comunicativas. A sociedade em rede, ao oportunizar que diversos sujeitos possam conectar-se através das redes de computadores, amplia a participação social em esferas públicas, de forma individual ou coletiva. Essas esferas são espaços emergentes, nos quais interesses gerais são expostos, controvertidos, debatidos, criticados para, então, dar lugar a um julgamento, síntese ou consenso.

Nesse sentido, as tecnologias digitais contribuíram para o desenvolvimento e a difusão de esferas públicas, centradas na interação, a exemplo dos sites de redes sociais (Facebook, Twiter), aplicativos (WhatsApp) e gêneros discursivos nos meios digitais (Blog, Email), ampliando os espaços da ação discursiva no cotidiano das pessoas e legitimando essas formas de interação mais amplas, públicas e linguisticamente híbridas.

Por essa lógica discursiva, a participação dos sujeitos nessas esferas públicas é estabelecida por meios linguísticos. Isso porque a interação linguística tem o potencial de conduzir os participantes do discurso a uma racionalidade comunicativa, que visa ao entendimento entre as pessoas, levando-se em conta a argumentação dos interagentes. A linguagem, então, constitui um processo importante para a integração das pessoas na sociedade em rede, onde as ações discursivas são mediadas pelas tecnologias digitais. Assim, o sujeito - inserido em um cenário interconectado - desenvolve capacidades linguísticas e comunicativas que viabilizam a sua participação nesses espaços públicos.

Este artigo, de natureza teórica, reflete sobre a ação discursiva no contexto das novas esferas públicas na sociedade em rede, tendo como base a Teoria do Agir Comunicativo, de Jürgen Habermas. Para isso, apresentam-se, inicialmente, as esferas públicas enquanto espaços comunicativos que, na sociedade atual, também são mediados pelas tecnologias digitais. Em seguida, explicita-se sobre a racionalidade comunicativa e a ação discursiva, atentando-se para a formação de competências linguísticas e comunicativas que possibilitam aos sujeitos interagirem nesses espaços comunicacionais, a partir de uma lógica argumentativa. Finalizando, reflete-se sobre o papel das instituições escolares na formação de um sujeito discursivo, que problematize as pretensões de validade do discurso e, assim, restabeleça a ação comunicativa.

\section{SOCIEDADE EM REDE E ESFERA PÚBLICA}

As tecnologias digitais constituem-se enquanto produto humano e construção social e integram o mundo em redes globais de instrumentalidade, ampliando, assim, a sociedade em rede. Para o sociólogo Manuel Castells (2005), a sociedade em rede, de base tecnológica, é fundamentada na microeletrônica e em redes digitais de computadores. Esse sistema de nós interligados são estruturas abertas "que evoluem acrescentando ou removendo nós de acordo com as mudanças necessárias dos programas que conseguem atingir os objetivos de performance para a rede" (CASTELLS, 2005, p. 20). 
As redes tecnológicas digitais têm como características flexibilidade e adaptabilidade. Estabelecem-se como recurso indispensável para a sociedade atual, pois transcendem fronteiras e integram as redes globais de capital, bens, serviços, comunicação, informação, ciência e tecnologia. Rede é "um conjunto de nós interconectados. A formação de redes é uma prática humana muito antiga, mas as redes ganharam vida nova em nosso tempo transformando-se em redes de informação energizadas pela internet” (CASTELLS, 2003, p. 7).

As tecnologias digitais possibilitam a difusão e/ou a transformação dos processos de comunicação, pois se relacionam ao homem, oportunizando ações comunicativas, de forma livre e democrática (CASTELLS, 2013). Isso permite notar mudanças estruturais na sociabilidade entre as pessoas e a emergência de indivíduos em rede ou sujeitos interconectados: aqueles que interagem a partir desses ambientes digitais. A internet, força motriz dessa sociedade, oportunizou a criação de novos espaços públicos, caracterizados pela liberdade de comunicação (CASTELLS, 2013).

A esfera pública representa um espaço comunicativo comum e participativo (HABERMAS, 1984). Constitui-se como um lugar de formação de opinião, onde diversos assuntos podem ser tematizados, criticados, justificados etc. No entanto, o sujeito, para participar de uma esfera pública, deve ter a capacidade de argumentação e de crítica. Ou seja: "o sujeito da esfera pública é o público enquanto portador da opinião pública: à sua função crítica é que se refere à 'publicidade' (Publizität) (HABERMAS, 1984, p.14). Assim, a esfera pública é o ambiente de formação e expressão da opinião pública, por meios linguísticos.

Entretanto, o surgimento de esferas públicas não se constitui em fato oriundo da sociedade interligada por redes digitais. Habermas (1984), em seu livro Mudança estrutural da esfera pública, retratou aspectos característicos dessa esfera desde o século XVIII. Um dos aspectos apresentados pelo filósofo diz respeito à aparente democratização desse espaço que, na verdade, era constituído pela burguesia, que "é o público que lê" (HABERMAS, 1984, p. 37). As qualificações de um homem privado para ter acesso à esfera pública, nesse período, consistiam em propriedades econômicas e formação educacional.

A institucionalização da esfera pública no Estado de direito burguês apresentou-se a partir de contradições, pois, ao mesmo tempo que projetava comunicação ao público, portanto, "em princípio, a todos os súditos; comumente, ela não atinge, assim, 'o homem comum', mas, se muito, 'as camadas públicas"' (HABERMAS, 1984, p. 37). Dessa forma, grande parte da população permanecia excluída dos critérios apresentados para o acesso à esfera pública.

$\mathrm{Na}$ sociedade atual, existem sujeitos que não têm participação ativa em diversas esferas públicas cotidianas, apesar de esses espaços caracterizarem-se como ambientes abertos, onde diversos assuntos podem ser tematizados (a exemplo de normas comuns, entendimentos culturais, aspectos de identidade etc.). Isso devido à dominação sistêmica da comunicação linguística. Quando isso ocorre, os sujeitos tornam-se impessoais em suas interações, impossibilitando a interlocução entre eles e os diversos grupos sociais que acessam as redes de computadores.

$\mathrm{Na}$ sociedade em rede, essa dominação acontece, por exemplo, em diversos setores no espaço público, tais como em redes sociais culturais, religiosas, 
jornalísticas, educacionais etc., artefatos esses que, muitas vezes, tornam-se burocráticos e mercantilistas e, por isso, se apoderam "[...] dos processos espontâneos de formação da opinião e da vontade, privando-os de seus conteúdos" (HABERMAS, 2012b, p. 588). Em contrapartida, a racionalidade comunicativa que estabelece a interação e a emancipação comunicativa - permite aos sujeitos participarem, de forma autônoma, dessas diversas esferas públicas.

\subsection{LINGUAGEM E RACIONALIDADE COMUNICATIVA}

A linguagem, na Teoria do Agir Comunicativo, constitui-se como elemento essencial para a interação social a partir de ações comunicativas, e tem como mecanismo a integração entre as pessoas. Assim, a linguagem representa "uma prática interativa, na qual uma forma de vida se reflete e, ao mesmo tempo, se reproduz" (HABERMAS, 1990, p. 112). Para estruturar sua teoria das ações linguísticas, Habermas (1990) lança mão da teoria dos atos de fala, de John Austin. Inicialmente, o filósofo descreve "os proferimentos linguísticos como atos através dos quais um falante gostaria de chegar a um entendimento com outro falante sobre algo no mundo" (HABERMAS, 1990, p. 65).

Devido a isso, os atos de fala são diferenciados de ações não-linguísticas. Como enfatiza Habermas (1990), os atos não-linguísticos não possuem a capacidade de autointerpretação reflexiva peculiar aos atos linguísticos. Além disso, os atos linguísticos são proferidos a depender de um fim e sucesso comunicativos. Assim,

Um ato de fala revela a intenção do falante; um ouvinte pode deduzir do contexto semântico do proferimento o modo como a sentença proferida é utilizada, ou seja, pode saber qual é o tipo de ação realizada através dele. As ações linguísticas interpretam-se por si mesmas, uma vez que possuem uma estrutura auto-referencial (HABERMAS, 1990, p. 67).

Para aprofundar a reflexão sobre a racionalidade comunicativa, Habermas (1990) parte da ideia de que a linguagem é uma forma de atividade humana. Esse contexto surge do diálogo desse autor com a Teoria dos Atos de Fala, de John Austin. Em uma conferência proferida por Austin (1990), intitulada Performativos e Constativos, ele deixa clara a identidade entre linguagem e ação, quando diz:

Por mais tempo que o necessário, os filósofos acreditaram que o papel de uma declaração era tão somente o de "descrever" um estado de coisa, ou declarar um fato, o que deveria fazer de modo verdadeiro ou falso. Os gramáticos, na realidade, indicaram com freqüência que nem todas as sentenças são (usadas para fazer) declarações, há tradicionalmente, além das declarações (dos gramáticos), perguntas e exclamações, e sentenças que expressam ordens, desejos e concessões (AUSTIN, 1990, p. 21). 
O caráter de ação está evidente na medida em que as palavras não servem apenas para declarar ou descrever fatos. Para explicar essa proposição, Austin (1990) faz distinção entre sentenças performativas e sentenças constativas. As sentenças constativas correspondem a declarações ou descrições de fatos. Já as performativas, a realização de ações proferidas. No entanto, as sentenças devem ser emitidas por pessoas autorizadas e em contextos apropriados.

Ainda sobre os atos performativos, Austin (1990) apresenta as condições de felicidade e de infelicidade desses atos. Para que exista uma sentença performativa feliz, é necessária a certeza de um procedimento convencional, ou seja, palavras adequadas proferidas por pessoas e contextos também adequados. Em contrapartida, uma sentença performativa pode ser infeliz; quando sujeito à crítica, o proferimento pode tornar-se um desacerto ou um ato intencionalmente nulo.

A Teoria dos Atos de Fala de Austin sustenta-se a partir do proferimento performativo feliz. Essa teoria refere-se a três tipos de atos: locucionário, ilocucionário e perlocucionário. $\mathrm{O}$ ato locucionário corresponde ao dizer algo; é a sequência de palavras que produz frases bem estruturadas; as orações e os enunciados pelos quais o falante expressa "estado de coisas". O perlocucionário designa a ação ou o efeito do dito no interlocutor em relação a sentimentos, pensamentos ou ações. Já o ilocucionário - base da Teoria do Agir Comunicativo - corresponde às ações que o falante pretende realizar quando produz o enunciado, ou seja, se faz uma promessa, uma confissão etc.

Os atos ilocucionários, então, representam a força motriz para o uso interativo da linguagem em diversas esferas públicas comunicacionais, pois têm como finalidade gerar o entendimento mútuo. Assim, quando os interlocutores compreendem e aceitam as suas ações de fala, diz-se que houve um sucesso ilocucionário. Sobre isso, Habermas (2012, p. 484) assegura:

Com a força ilocucionária de uma externação, o falante pode motivar o ouvinte a aceitar sua oferta de um ato de fala e, com isso, motivá-lo a estabelecer uma ligação racionalmente motivada. Tal concepção prevê que sujeitos aptos a falar e agir possam fazer referência a mais que um único mundo; e que, ao se entenderem uns com os outros sobre alguma coisa em um mundo único, embasem sua comunicação sobre um sistema de mundos que suponham de maneira compartilhada.

Entretanto, como afirma Habermas (2012), a intenção comunicativa do falante e o objetivo ilocucionário que ele almeja resultam do significado manifesto do que se diz. Assim, os atos de fala são considerados autoidentificadores. Isto é: ao realizar um proferimento, o falante tem a intenção de que se compreenda o que ele diz, se é uma saudação, ordem, admoestação, explicação, etc. "Sua intenção comunicativa esgota-se no fato de que cabe ao ouvinte entender o teor manifesto da ação de fala" (HABERMAS, 2012, p. 503).

Para ilustrar sua explicação, Habermas (2012) apresenta o seguinte exemplo: quando alguém, diante de outra pessoa, diz que pediu demissão da empresa onde trabalhava, o ato de fala terá sucesso ilocucionário se o ouvinte entender essa asserção e aceitá-la como verdadeira. Assim, é possível dizer que ocorreu um 
entendimento mútuo racionalmente motivado. Dessa forma, compreende-se que o sucesso do ato ilocucionário acontece no plano das relações interpessoais em que os participantes da interação se entendem mutuamente uns com os outros sobre alguma coisa que está no mundo.

A partir das ações linguísticas é concebida duas formas de interação: a comunicativa (voltada ao entendimento mútuo) e a estratégica (voltada à obtenção de um fim desejado). E é a partir da ação comunicativa dentro dos atos de fala da linguagem que Habermas (1990) desenvolve a Teoria do Agir Comunicativo.

A ação comunicativa, então, é o resultado do sucesso das sentenças ilocucionárias; a sua realização corresponde ao "tipo de interações em que todos os participantes buscam sintonizar entre si seus planos de ação individuais" (HABERMAS, 2012, p. 509). No entanto, as interações mediadas pela linguagem em que os participantes desejam fins perlocucionários, o filósofo denomina como agir estratégico.

$\mathrm{Na}$ ação comunicativa, através de um ato de fala, o locutor procura se entender a respeito de algo com um ouvinte. Mas, para isso, o ato de fala deve ser compreendido pelo ouvinte e, caso possível, aceito por ele. Sobre isso, Habermas (2004, p. 108) assegura que

A racionalidade do uso lingüístico orientado para o entendimento mútuo depende então de os atos de fala serem de tal modo compreensíveis e aceitáveis que, por meio deles, o falante alcance (ou possa alcançar sob circunstâncias normais) êxitos ilocucionários.

A capacidade de fundamentar exteriorizações racionais está ligada à disposição que as pessoas possuem de se exporem à crítica e de participarem de argumentações. Exteriorizações racionais, em virtude da possibilidade de serem criticadas, também são passíveis de correção. Então, "o que torna aceitável a oferta do ato de fala são, em última análise, as razões que o falante, no contexto dado, poderia apresentar para a validade do dito" (HABERMAS, 2004, p. 109). A racionalidade comunicativa, entretanto, tem como horizonte a linguagem, através da qual são estruturadas as formas de vida social e iniciada a interação simbólica entre os diversos atores sociais.

\section{RACIONALIDADE COMUNICATIVA E AÇÃO DISCURSIVA NA SOCIEDADE EM REDE}

$\mathrm{Na}$ sociedade atual, a linguagem assumiu uma dimensão que requer uma análise complexa para entendê-la, fruto de novos conceitos e suportes tecnológicos. Dessa forma, a linguagem, enquanto meio que proporciona o diálogo entre as pessoas com vistas a chegarem a um comum acordo, a partir de atividades discursivas e comunicativas, torna-se o fio condutor da interação nas esferas públicas. 
Nesse sentido, a linguagem não é só concebida como meio que veicula informações ou gera a comunicação; mas, também, como condição a partir da qual a compreensão, o conhecimento objetivo, a representação individual e coletiva tornam-se possíveis. Ao estabelecer relações intersubjetivas ao mesmo tempo em que se refere a objetos no mundo, a linguagem incorpora uma estrutura proposicional e performativa: a primeira, relacionada a proposições que apresentam o objetivo ou conteúdo da comunicação; a segunda, diz respeito ao tipo de comunicação intersubjetiva que será estabelecida (se a proposição é verdadeira, se a pessoa foi sincera ao proferi-la etc.).

Nessas relações, a linguagem é uma realidade intersubjetiva; linguagem e sujeito se implicam mutuamente. Nesse ínterim,

[...] os sinais linguísticos, que serviam apenas como instrumento e equipamento das representações adquirem, como reino intermediário dos significados lingüísticos, uma dignidade própria. As relações entre linguagem e mundo, entre preposição e estados de coisas, substituem as relações sujeito-objeto. O trabalho de constituição do mundo deixa de ser uma tarefa de subjetividade transcendental para se transformar em estruturas gramaticais (HABERMAS, 1990, p. 15).

A comunicação linguística é um processo que se efetiva em sociedade e se torna condição essencial para a interação do sujeito com o mundo. Assim, é através do diálogo-comunicativo, não coercitivo, que o sujeito do conhecimento se percebe individualizado e, dessa forma, profere atos de fala coerentes, de forma autônoma e livre, que refletem as condições específicas de cada esfera de comunicação.

É a essa ação, inerente ao ser humano, que Habermas (1990b) chama de racionalidade. A partir desse conceito de racionalidade, oriundo da viragem linguística, é apresentada a racionalidade comunicativa, expressa de um entendimento descentrado do mundo. Ao apresentar esse tipo de racionalidade, o filósofo estabelece a dimensão comunicativa da razão à necessidade de consenso entre as pessoas, pelo diálogo. $\mathrm{O}$ consenso, que não se trata de algo absoluto e universal, mas uma relação estabelecida de forma dinâmica e interativa, representa o estar de acordo com as pretensões de validade propostas pelo locutor.

Habermas (2012) afirma que a razão comunicativa faz-se valer da força de coesão, da compreensão intersubjetiva e do conhecimento mútuo, comunicativamente. Com o uso comunicativo da linguagem, o objetivo é entenderse com alguém a respeito de alguma coisa no mundo. Não se pode esquecer, entretanto, que para alcançar esse entendimento mútuo, além da dimensão social e intersubjetiva da linguagem, deve ser levado em conta o papel da argumentação. Os sujeitos que participam de uma argumentação demonstram racionalidade na maneira em que agem e respondem às razões a favor ou contrárias ao que são apresentadas em um diálogo.

No entanto, ao apresentar a concepção de racionalidade comunicativa, o filósofo faz uma distinção entre dois modos de comunicação: a ação comunicativa e a ação discursiva. $\mathrm{Na}$ ação comunicativa, os sujeitos trocam informações sem, contudo, problematizar os enunciados proferidos pelo interlocutor. Em relação à 
ação discursiva, existe a problematização de pretensões de validade expressas pelo locutor. Nesse sentido, a primeira refere-se a opiniões; a segunda, a normas, as quais são sustentadas pelo jogo linguístico utilizado para chegar ao consenso.

O discurso, então, é a própria argumentação: "denominamos argumentação como o tipo do discurso em que os participantes tematizam pretensões de validade controversas e procuram resolvê-las ou criticá-las com argumento" (HABERMAS, 2012, p. 48). Nesse ínterim, "um argumento contém razões que se ligam sistematicamente à pretensão de validade de uma exteriorização problemática" (HABERMAS, 2012, p. 48). Um discurso, por sua constituição argumentativa, leva em conta duas importantes situações: a adequação da linguagem (a depender dos atores da interação, esfera pública comunicacional, tematização etc.) e adequação de julgamento do fenômeno (a partir das pretensões de validade).

Ao estabelecer uma interação, Habermas (2012) destaca que os sujeitos levantam quatro pretensões de validade do discurso: verdade, sinceridade, compreensibilidade e correção. A pretensão à verdade objetiva a superação de conceitos e da linguagem considerados, pelos interlocutores, como inadequados; visa à coerência com o estado de coisas sobre o qual se diz. Na pretensão à correção, os interlocutores justificam e julgam as ações linguísticas de forma imparcial. Espera-se, também, que os sujeitos apresentem boa formulação de enunciados e se disponha a explicar suas expressões simbólicas (compreensibilidade) e, por fim, que haja sinceridade ao proferir os enunciados.

Para justificar as asserções como verdadeiras, os falantes utilizam-se do discurso teórico, que se constitui como uma continuação da ação orientada para o entendimento. Nesse tipo de discurso, é tematizada pretensão de validade ligada ao mundo objetivo (neste caso, a verdade do proferimento). Já o discurso prático permite tematizar se uma determinada ação ou norma de ação é correta. No entanto, as normas válidas devem ser aprovadas racionalmente por todos que fazem parte do momento da interação.

Tanto o discurso teórico quanto o discurso prático apresentam uma referência a percepções sensoriais interpretadas e as necessidades comunicativas do locutor. Em relação ao discurso explicativo, é necessária a ação de tornar claro algo incompreendido por um integrante da interlocução. Esse discurso está ligado ao comportamento do intérprete, que pode apresentar dificuldade de compreensão dos proferimentos do locutor.

Logo: o discurso teórico tem a pretensão à verdade. Assim, o locutor "se esforça não somente em avaliar o conflito de modo imparcial, sob pontos de vista morais, mas também em superá-los de modo consensual, não seguindo simplesmente seus afetos e interesses imediatos" (HABERMAS, 2012, p. 50). Visa à superação de conceitos considerados inadequados pelos interlocutores. Para isso, o discurso teórico apresenta-se a partir de quatro etapas: problematização da asserção, explicação teórica da asserção problematizada, discurso metateórico (epistemologia) e passagem para o nível da auto-reflexão (SIEBENEICHLER, 1989).

O discurso prático permite tematizar pretensões à correção normativa. Nessa conjuntura, é racional quem justifica suas ações e julga de forma imparcial. Isto é: "denominamos racional uma pessoa [...] quando ela é capaz de assumir uma postura 
reflexiva diante dos próprios padrões valorativos que interpretam as carências elementares" (HABERMAS, 2012, p. 52). Isso se desenvolve a partir da entrada dos interlocutores no nível do discurso, com base na problematização de proibições e valores, discurso metaético e passagem para a reflexão sobre o fato (SIEBENEICHLER, 1989). Já o discurso explicativo é a forma de argumentação que visa à compreensibilidade. Para isso, é necessário que o sujeito apresente boa formulação (linguística, estrutural, semântica, sintática) de enunciados e se disponha a explicar suas expressões simbólicas.

Para a veiculação desses discursos, é proposta a existência de uma lógica argumentativa, que é composta por três aspectos: produtos, procedimentos e processos. No plano lógico dos produtos, as argumentações são destinadas "a produzir argumentos concludentes, capazes de convencer com base em propriedades intrínsecas e com os quais se podem resgatar ou rejeitar pretensões de validez" (HABERMAS, 1989, p 110). Esse plano apresenta as regras de uma lógica mínima:

a.1) A nenhum falante é lícito contradizer-se.

a.2) Todo falante que aplicar um predicado $\mathrm{F}$ a um objeto $a$ tem que estar disposto a aplicar $\mathrm{F}$ a qualquer outro objeto que seja semelhante a $a$ sob todos os aspectos relevantes.

a.3) Não é lícito aos diferentes falantes usar a mesma expressão com sentidos diferentes (HABERMAS, 1989, p. 110).

Ao observar essas regras, os interlocutores têm por finalidade produzir consenso na comunicação, levando-se em conta o sentido da argumentação. Dizse, então, que um sujeito é racional ao empreender um processo interativo, à medida que seus proferimentos são coerentes interna e externamente, além de semanticamente aceitável.

Em relação ao plano dialético dos procedimentos, as argumentações aparecem como processos de entendimento mútuo que são regulados para que proponentes e oponentes possam, a partir de atitudes hipotéticas e da experiência, examinar as pretensões de validez que se tornam problemáticas. Os interlocutores, nesse plano, buscam cooperativamente e dialogicamente a verdade. Para isso, tornase necessário o reconhecimento da imputabilidade e da sinceridade de todos os participantes para que, através do melhor argumento, obtenham um acordo racionalmente motivado. Dessa forma,

b.1) A todo falante só é lícito afirmar aquilo em que ele próprio acredita.

b.2) Quem atacar um enunciado ou norma que não for objeto da discussão tem que indicar razões para isso (HABERMAS, 1989, p. 111).

Em relação aos procedimentos, é necessário que os sujeitos apresentem seus argumentos de forma sincera para que a interação possa ser continuada. Além disso, leva-se em conta também a relevância da argumentação, a contribuição dos 
participantes e a justificação de suas opiniões com o objetivo de restabelecer a ação comunicativa. Como destaca Habermas (1989), tanto o sentido quanto a sinceridade devem ser satisfeitos para que o processo argumentativo seja válido. Assim, quando uma dessas lógicas não é observada pelos interlocutores, a argumentação fica enfraquecida.

Nesse plano retórico, o discurso apresenta-se como um processo comunicacional, que deve satisfazer condições de fala para alcançar um acordo racionalmente motivado. Nesse sentido, Habermas (1989) apresenta os pressupostos universais pragmáticos necessários ao discurso como determinações de uma situação ideal de interação, que está livre da repressão e da desigualdade. Dessa forma, os participantes devem neutralizar todo e qualquer motivo que não seja a busca cooperativa pela verdade. Habermas (1989, p. 112) apresenta as seguintes regras do Discurso:

c.1) É lícito a todo sujeito capaz de falar e agir participar de Discursos.

c.2) a. É lícito a qualquer um problematizar qualquer asserção.

b. É lícito a qualquer um introduzir qualquer asserção no Discurso.

c. É lícito a qualquer um manifestar suas atitudes, desejos e necessidades.

c.3) Não é lícito impedir falante algum, por uma coerção exercida dentro ou fora do Discurso, de valer-se de seus direitos estabelecidos em (c.1) e (c.2).

Nesse plano, existe a inclusão de todos os participantes, sem exceção, que disponham da capacidade em participar de argumentações (c.1); com chances iguais de contribuição ao debate, fazendo valer seus argumentos (c.2); em condições de comunicação que tornem possível prevalecer o direito a um acesso universal ao discurso e chances iguais de participar dele (c.3). No plano lógico dos processos, as regras para a participação de sujeitos no discurso prático são situadas. Assim, esses elementos se tornam pressupostos inevitáveis para a comunicação.

Ao apresentar esses três aspectos para o plano discursivo - produto, procedimento e processo -, Habermas (1989) deixa clara a necessidade de se observar todos eles em conjunto para que ocorra a interação. Nesse sentido, ao se instaurar uma ação discursiva, o sujeito deve valer-se de argumentos que sejam capazes de comprovar as pretensões de validez, por meios linguísticos.

Argumentos, então, são meios com os quais os interlocutores podem obter o reconhecimento intersubjetivo de uma pretensão de validade levantada pelo proponente de forma hipotética, gerando, assim, o saber a partir de opiniões. As argumentações têm por objetivo promover a superação de uma situação que se cria pela problematização das pretensões de validade pressupostas na ação comunicativa. Para argumentar, o sujeito apoia-se em hipóteses reconstrutivas, tais como: diferenciar as pretensões de validade de pretensões de poder e submeter proferimentos que levantam pretensões de validez a análise semântica dos enunciados (HABERMAS, 2012).

Nessas interações, nas esferas públicas contemporâneas mediadas pelas tecnologias digitais, os interagentes levantam pretensões de validade com seus atos de fala em relação à veracidade de seu argumento (discurso teórico), à 
inteligibilidade produzida por ele (discurso explicativo) e à correção desse argumento (discurso prático). E é sob essa perspectiva que se restabelece a ação comunicativa, necessária para a constituição do sujeito crítico e emancipado, que se apresenta ao mundo de forma competente através de mecanismos linguísticos e comunicativos.

\title{
3.1 AÇÃO LINGUíSTICO-COMUNICATIVA
}

$\mathrm{Na}$ sociedade em rede, as esferas públicas têm o imperativo de fazer emergir o sujeito competente, capaz de fala e ação, a partir das relações sujeito-sujeito. A interação, então, ocorre entre duas ou mais pessoas que, ao conversarem entre si sobre algo no mundo, levantam com seus atos de fala pretensões de validade e, ao aceitarem-nas, chegam a um acordo racionalmente motivado.

Nesse sentido, Habermas (1989) concebe o locutor competente (falante responsável pelo que diz) enquanto aquele que transforma sentenças em enunciados. No entanto, o falante competente também tem ciência de que seus discursos são submetidos a situações comunicativas e dialógicas para, dessa forma, serem aceitos pelos integrantes da comunicação.

O proferimento linguístico aponta em duas direções unívocas: o mundo e o destinatário. Isto é: para ocorrer o entendimento entre pessoas envolvidas em processos interativos, não basta apenas o reconhecimento intersubjetivo dos atos de fala, mas é necessário também o conhecimento do nível de objetos ou de estado de coisas sobre os quais os indivíduos se comunicam uns com os outros.

Sobre isso, destaca-se que

\begin{abstract}
Em qualquer processo de entendimento do mais simples ao mais complicado, todos os partidos apóiam-se num ponto de referência comum: o de um consenso possível, mesmo que este ponto de referência seja esboçado a partir do respectivo contexto individual, porque idéias tais como verdade, racionalidade ou justificação, desempenham a mesma função gramatical em toda a comunidade linguística, mesmo que venham a ser interpretadas diferentemente e aplicadas de acordo com critérios distintos (HABERMAS, 1990, p. 175).
\end{abstract}

A competência linguístico-comunicativa no proferimento de um discurso, ou seja, a competência interacional e comunicativa tem por objetivo gerar a reflexão da ação que, quando obtida de forma dialógica, promove a emancipação do indivíduo. Mas para isso os interagentes problematizam pretensões de validade verdade e correção -, de forma argumentativa, com o objetivo de obter o entendimento mútuo. Assim,

[...] o entendimento por via linguística é apenas o mecanismo da coordenação da ação que, em face dos planos de ação e das atividades propositadas dos envolvidos, integra tais planos e atividades à interação (HABERMAS, 2012, p. 184). 
Com a observância desses pressupostos (coordenação de ação e integração de ação e de atividades) considerados inevitáveis, Habermas (1989) entende que nas relações de interação ocorrerá uma maior liberdade para participação, de forma igualitária, dos sujeitos, oportunizando chances de escolha e de realização de atos de fala de forma livre. Nesse sentido, os participantes da comunicação atribuem esforços para a obtenção do consenso, através da resolução de mal entendidos comunicativos, sempre levando em conta a igualdade comunicativa (utilização dos atos de fala) e igualdade de fala (problematização de pretensões de validade).

\section{ESFERA PÚBLICA E SUJEITO DISCURSIVO}

Para se conceber uma sociedade em rede estrategicamente ligada pelas tecnologias digitais é necessário, a priori, que os sujeitos que dela participam estabeleçam-se a partir de esferas públicas. Esse espaço, que representa uma ampliação de outros ambientes comunicacionais, não se constitui em um sistema, instituição ou organização; nem é uma esfera fechada sem interpenetração de outras esferas. "Mas se produz, como mundo da vida no todo, por meio do agir comunicativo de forma geral, compreensível [...]” (REESE-SCHÄFER, 2012, p. 175).

O sujeito é formado por ações linguísticas e são essas ações que geram o processo de individuação (HABERMAS, 1990, 2012b) medido "não somente pela diferenciação de identidades singulares, mas também pelo crescimento da autonomia pessoal" (HABERMAS, 1990, p. 219). Dessa forma, para que aconteça a interação na esfera pública em uma sociedade em rede, "o elemento individual deve ser caracterizado como sendo o essencial [...]” (HABERMAS, 1990, p. 184).

A individuação (selbst) resulta na autonomia do sujeito. Ela se forma através de um processo de socialização linguisticamente mediado; da consciência que o sujeito tem sobre si mesmo; do meio do entendimento linguístico com o outro e consigo mesmo. O "eu" autônomo é aquele que se opõe ao argumento coercitivo fruto de mecanismos sistêmicos, a exemplo do poder político, econômico etc. Ele surge não mais com o papel de observador, "mas como um falante, e aprende a se ver e a se compreender na perspectiva social de um ouvinte com o qual se depara no diálogo" (HABERMAS, 1990, p. 206).

Para os indivíduos, a individualização social "significa que se espera deles uma autodeterminação e uma auto-realização que pressupõe uma identidade-eu de tipo não convencional" (HABERMAS, 1990, p. 218). No entanto, nos processos comunicativos em uma sociedade em rede, é possível uma esfera pública que contribua para a individuação do sujeito, tornando-o autônomo e consciente?

A resposta a essa pergunta representa uma tarefa complexa, porém, necessária. Nas esferas públicas contemporâneas, para que ocorra o entendimento mútuo, o diálogo deve ser mediado linguisticamente e não por elementos coercitivos que fazem parte do mundo sistêmico. Isso porque a comunicação mediada pela linguagem denota uma alternativa que evidencia as individualidades pessoais, a consciência intersubjetiva e a autonomia social. 
Dessa forma, nessas esferas públicas, espera-se a emergência de mecanismos reais para o exercício da democracia, em que os sujeitos comunicativos atuem linguisticamente sobre o mundo, de forma verdadeira, correta, sincera e compreensível. A partir da articulação de saberes, as pessoas estruturam, racionalmente, seu pensamento, ideia, argumento, opinião, de forma que sejam provocadas ao diálogo e que, através do debate, cheguem a um acordo sobre algo no mundo.

Um proferimento é cheio de nuanças dialógicas, sendo que esse é constituído, inicialmente, pela experiência discursiva individual dos sujeitos e ampliado através das constantes interatuações entre as pessoas. Assim, o ato de fala de um sujeito apresentará êxito se o outro sujeito da interlocução aceitar os enunciados nele contido em face de pretensões de validez. Além disso,

Sob o aspecto funcional do entendimento, a acção comunicativa serve para a transmissão e renovação do saber cultural; sob o aspecto da coordenação de ações visa à integração social e ao estabelecimento de solidariedade; sob o aspecto da socialização, por fim, a acção comunicativa ajuda a estruturar identidades pessoais (HABERMAS, 2010, p. 158).

O conceito de entendimento mútuo proposto por Habermas tem a intenção de demonstrar como os mecanismos de fala atuam diretamente na construção social do real por meio dos acordos intersubjetivos e da subjetividade construída pela interação. A subjetividade é embasada pela linguagem, pela capacidade de indivíduos tornarem-se sujeitos linguísticos, que usam adequadamente a linguagem nos contextos em que participam. Nessa perspectiva, preenche três funções comunicativas: (i) a função de reprodução cultural, (ii) a função da integração social e a (iii) a função da socialização da interpretação cultural das necessidades.

Nas relações discursivas cotidianas, falante e ouvinte não interagem com a linguagem como se fosse um sistema abstrato de normas, pois a língua não representa apenas um conjunto de signos que se combinam para estabelecer comunicação. $\mathrm{Na}$ perspectiva da racionalidade comunicativa, "a linguagem e a experiência não se apresentam sob as condições transcendentais da ação enquanto tal" (HABERMAS, 1982, p. 214), pois essa ultrapassa a linguagem da gramática cotidiana, a qual regula elementos verbais e não-verbais de uma práxis exercida habitualmente.

A auto-relação refletida, que se constrói pela comunicação linguística, pode ser entendida de três formas: epistêmica, técnica e moral. A auto-relação epistêmica abarca a relação do sujeito com ele mesmo, a partir de uma atitude reflexiva do sujeito cognoscente para com suas opiniões e convicções. A auto-relação técnica reflete uma atitude do sujeito agente para com sua própria atividade orientada a fins. Já a auto-relação moral diz respeito ao ator que age comunicativamente e exige uma atitude de reflexão ante o projeto da própria vida.

Habermas (2004) destaca que a auto-relação é uma condição essencial para a liberdade reflexiva (atitude teórica), liberdade de arbítrio (escolhas racionais) e 
liberdade ética (estabilização de uma identidade do eu), elementos que fazem parte das racionalidades dos sujeitos no sentido do conhecer, do agir e do falar.

Dessa forma, entende-se que a racionalidade comunicativa refere-se à capacidade do sujeito de estabelecer relações com fatos, com objetos, com outros sujeitos, com desejos e sentimentos, pois essas ações refletem as referências para a veracidade e autenticidade dos discursos. Desse contexto, infere-se o surgimento do sujeito discursivo.

O sujeito discursivo, então, é aquele que transita entre a esfera comunicativa e a esfera discursiva. Estabelece relação epistêmica, técnica e moral, ao proferir argumentos competentes. Transforma a interação em um espaço onde os conflitos entre a pré-compreensão e a ação comunicativa são estabelecidos discursivamente. Esse sujeito, em seu processo discursivo, leva em conta pressuposições comunicativas, tais como:

(a) inclusão e caráter público: não pode ser excluído ninguém desde que tenha uma contribuição relevante a dar no contexto de uma pretensão de validade controversa; (b) igualdade comunicativa de direitos: todos têm a mesma chance de se manifestar sobre um tema; (c) exclusão da ilusão e do engano: os participantes têm que acreditar no que dizem; (d) ausência de coações: a comunicação deve estar livre de restrições que impedem a formulação do melhor argumento capaz de levar a bom termo a discussão (HABERMAS, 2007b, p. 60-61).

Nessa perspectiva, para que o sujeito desenvolva competências linguísticas e comunicativas que viabilizam a sua participação de forma livre e democrática em diversas esferas públicas, as instituições escolares apresentam-se como lócus por contribuírem com a utilização, de forma consciente, das estruturas linguísticas em função de necessidades comunicativas das pessoas.

A linguagem constitui um agente importante para a integração das pessoas em sociedade. Assim, a ação educativa na escola compreende o processo de aprendizagem do aluno a partir de sua formação discursiva. Isso significa que ensinar - atividade necessária para o desenvolvimento das capacidades de falar e agir - tem como uma de suas finalidades possibilitar que o discente pronuncie atos de fala, orientados pelo melhor argumento, em diversas esferas públicas que necessite participar.

\subsection{ESFERA PÚBLICA E INTERAÇÃO NA SOCIEDADE EM REDE}

Ratifica-se, nesse momento, que a esfera pública é um espaço dialógico por excelência, fundamentado na capacidade de confrontar argumentos racionais a partir da opinião de seus participantes. Os processos interativos dialógicos contribuem para a construção e transformação desses espaços públicos. Assim, a comunicação passa a constituir-se no espaço "[...] cognitivo em que as mentes das pessoas recebem informação e formam os seus pontos de vista através do processamento de sinais da sociedade do seu conjunto" (CASTELLS, 2005, p. 23). As opiniões, os debates, as controvérsias, concordâncias dos sujeitos se formam nesse espaço de comunicação. 
Os múltiplos espaços públicos são compreendidos enquanto prolongamento das relações sociais. Na atualidade, por exemplo, as tecnologias digitais são um canal mediador das interlocuções nesses locais, o que possibilita o crescimento no número de agentes que participam de redes interativas e comunicativas. Como resultado dessas participações, ocorre uma menor desigualdade de posição na esfera pública e, assim, uma maior fluidez em relação às tematizações.

Entretanto, para evitar que elementos não linguísticos colonizem o mundo da vida nessas esferas públicas, os sujeitos (capazes de fala e ação) devem estabelecer um diálogo social, prevalecendo o critério do melhor argumento. E é por esse movimento comunicativo que se desenvolve a intersubjetividade e a formação do sujeito discursivo.

No entanto, apesar de ser necessária uma interação cooperativa entre locutorouvinte através da comprovação das pretensões de validez, nem sempre na sociedade em rede esse propósito comunicativo é alcançado. Isso porque os discursos pragmáticos nesses espaços correspondem a possíveis contextos de uso comunicativo, em que nem sempre os enunciados apresentados na intercomunicação são compreensíveis, tendo em vista que a compreensão ultrapassa a significação hermenêutica e agrega um caráter responsivo ativo em relação aos valores e à vida dos participantes do ato de comunicação.

Além disso, nem sempre os enunciados apresentados na intercomunicação são verdadeiros e fazem parte de um discurso coerente. No entanto, para Habermas (2007, p. 60), a verdade deve transcender qualquer contexto dado de justificação, pois "[...] uma vez que uma proposição é verdadeira, ela é verdadeira para sempre e para qualquer público [...]”. Para que esta pretensão possa ser válida, é necessária uma comunicação que tenha como finalidade estabelecer interação além de uma realidade objetivada, mas sim uma realidade simbolicamente estruturada, ou seja, a partir do cotidiano das pessoas, no contexto natural do mundo vivido.

Nem sempre as pessoas, ao apresentarem seus enunciados na intercomunicação, são sinceras em relação a suas intenções comunicativas. O interlocutor pode não apresentar a intenção comunicativa tal qual é enunciada (HABERMAS, 2010). No modelo da ação comunicativa habermasiana, pressupõese a sinceridade dos participantes dos discursos, que renunciam a qualquer intenção enganadora. Essa pretensão de validade, que abarca manifestações consideradas expressivas - sentimentos, desejos, vontades - é percebida não a partir do discurso, mas sim da constância de um determinado comportamento.

Por fim, nem sempre os enunciados apresentados na intercomunicação são corretos normativamente. Nesse sentido, um sujeito falante, para ser considerado racional, deve justificar suas razões a partir de um contexto normativo válido (HABERMAS, 2014), que deve satisfazer a todos os participantes da comunicação. Dessa forma, expressões de orientação normativa - ordens, conselhos, promessas etc. - implicam uma pretensão de correção que transcende o mundo objetivo, transformando-se em algo assertivo racionalmente numa situação ideal de fala. 


\section{CONSIDERAÇÕES FINAIS}

A liberdade comunicativa refere-se ao direito de participação dos sujeitos nos processos interacionais, com independência e autonomia, através do discurso racional e com autoria responsável. Essa liberdade é despertada no sujeito pelas ações comunicativas performativas, que o levam a movimentar-se comunicativamente a partir do proferimento de argumentos em relação aos seus desejos e preferências, levando em conta padrões éticos e morais do discurso (SIEBENEICHLER, 2010). Para construir essas argumentações, espera-se que o locutor desenvolva-se enquanto sujeito competente linguístico-comunicativamente.

A comunicação em rede, característica da época atual, proporciona ao sujeito discursivo a possibilidade de participar de esferas públicas de forma democrática e livre. Essa participação fundamenta-se no diálogo e no discurso ético, livre de coação externa, pelo qual os participantes possam apresentar seus pontos de vista e submeter-se aos contra-argumentos de outras pessoas.

A interação que se pretende nas esferas públicas na sociedade em rede diz respeito à possibilidade de o sujeito participar de uma comunicação, levando em conta pretensões de validade do discurso. Entretanto, para esse ato comunicativo, os sujeitos comunicantes devem possuir autoria responsável (faculdade de posicionar-se criticamente diante de pretensões de validade questionáveis), conhecimento linguístico (capacidade que o usuário da língua possui em produzir e entender enunciados linguísticos) e comunicativo (competência que o sujeito possui de utilizar enunciados da língua em situações concretas de comunicação).

\section{REFERÊNCIAS}

AUSTIN, John L. Quando dizeré é faz̧er: palavras e ação. Tradução Danilo Marcondes de Souza Filho. Porto Alegre: Artes Médicas, 1990.

CASTELLS, Manuel. A sociedade em rede: do conhecimento à política. In: CASTELLS, Manuel; CARDOSO, Gustavo (org). A sociedade em rede: do conhecimento à política. Imprensa Nacional, 2005.

CASTELLS, Manuel. A galáxia da internet: reflexões sobre a internet, os negócios e a sociedade. Tradução Maria Luiza Borges. Rio de Janeiro: Jorge Zahar Editora, 2003.

CASTELLS, Manuel. Redes de indignação e esperança. Movimentos sociais na era da internet. Tradução Carlos Alberto Medeiros. Rio de Janeiro: Zahar Editora, 2013.

FREITAG, Barbara. A teoria crítica: ontem e hoje. 5 ed. São Paulo: Brasiliense, 1994.

HABERMAS, Jürgen. Mudança estrutural da esfera pública. Tradução Flávio Kothe. Rio de Janeiro: Tempos Modernos, 1984. 
HABERMAS, Jürgen. Teoria do agir comunicativo. Racionalidade da ação e racionalização social. Vol 2. Tradução: Flávio Beno Siebeneichler.São Paulo: WMF Martins Fontes, 2012b.

HABERMAS, Jürgen. Pensamento pós-metafísico: estudos filosóficos. Tradução Nachmetaphysisches Denken, Philosophische Ayfsätze. Rio de Janeiro: Tempo Brasileiro, 1990.

HABERMAS, Jürgen. Teoria do agir comunicativo: racionalidade da ação e racionalização social. Vol 1. Tradução Paulo Astor Soethe. São Paulo: Editora WMF Martins Fontes, 2012.

HABERMAS, Jürgen. Verdade e justificação: ensaios filosóficos. Tradução Milton Camargo Mota. São Paulo: Edições Loyola, 2004.

HABERMAS, Jürgen. O discurso filosófico da modernidade. Tradução Manuel José Simão Loureiro (capítulo XI). Lisboa: Publicações Dom Quixote, $1990 \mathrm{~b}$.

HABERMAS, Jürgen. Jürgen Habermas: obras escolhidas. Volume I. Tradução Lumir Nahodil. Lisboa: Edições 70, 2010.

HABERMAS, Jürgen. Conhecimento e interesse. Rio de Janeiro: Zahar Editores, 1982.

HABERMAS, Jürgen. Entre naturalismo e religião: estudos filosóficos. Rio de janeiro: Tempo Brasileiro, 2007b.

HABERMAS, Jürgen. Observações sobre o desenvolvimento da obra de Max Horkheimer. Tradução Maurício Chiarello. In: Educação e Filosofia. Uberlândia, v. 21, n. 42, p, 273-293, jul/dez, 2007.

HABERMAS, Jürgen. Jürgen Habermas: obras escolhidas. Volume II. Tradução Lumir Nahodil. Lisboa: Edições 70, 2014.

REESE-SCHÄFER, Walter. Compreender Habermas. Tradução Vilma Schneider. 4 ed. Petrópolis (RJ): Vozes, 2012.

SIEBENEICHLER, Flávio Beno. Jürgen Habermas: razão comunicativa e emancipação. Rio de Janeiro: Tempo Brasileiro, 1989.

SIEBENEICHLER, Flávio Beno. Razão comunicativa e técnicas de comunicação e informação em rede. In: GÓMEZ, Maria Nélida González; LIMA, Clóvis Ricardo Montenegro (org). Informação e democracia: a reflexão contemporânea da ética e da política. Brasília: Instituto Brasileiro de Informação em Ciência e Tecnologia, 2010. p. 9-29. 